\title{
AAdministração Pública Municipal como Fomentadora do Desenvolvimento Social e Econômico
}

\author{
The Municipal Public Administration as Sponsor of Social \\ and Economic Development
}

\author{
Maria Lírida Calou de Araújo e Mendonça
}

Universidade de Fortaleza, Fortaleza - CE, Brasil

\author{
Marcus Mauricius Holanda \\ Faculdade Luciano Feijão, Sobral - CE, Brasil
}

Resumo: Na conjuntura brasileira contemporânea, verifica-se que o desenvolvimento social não acompanha, de forma paralela, o crescimento econômico e que, além disso, há uma lacuna entre essas vertentes. Mesmo com a inserção, na Constituição da República Federativa do Brasil de 1988, de um extenso rol de direitos e de garantias fundamentais, a simples disposição não foi suficiente para conseguir o equilíbrio desejado. Portanto, surge o seguinte questionamento: qual seria a contribuição do município no desenvolvimento local, tanto social, quanto econômico? Como poderia, de forma efetiva, implementar o disposto no texto constitucional, com relação aos direitos e às garantias fundamentais? $\mathrm{O}$ trabalho almeja, portanto, por intermédio de uma metodologia objetiva, com uma análise de posicionamentos doutrinários e legais, demonstrar como a responsabilidade administrativa do município é condizente com os objetivos constitucionais, de modo a viabilizar e a concretizar o desenvolvimento local, tanto econômico como social.

Palavras-chave: Desenvolvimento Econômico e Social. Fomento Municipal. Administração Pública.
Abstract: In Brazilian contemporary conjucture, it is verified that not only social development does not accompany, in a parallel way, economic development, but also that there is a gap between these subjects. Even with the insertion, in 1988 Brazilian Federal Constitution, of an extensive list of fundamental rights and guarantees, a simple disposition was not enough to achieve the desired balance. Therefore, the following question arises: what would be the municipal contribution to local development, in both social and economic terms? How could it be effectively implemented the provided in Constitution, respecting fundamental rights and guarantees? Thus, the present work aims, through an objective methodology with an analysis of doctrinal and legal positions, to demonstrate how the municipal administrative responsibility is consistent with the constitutional objectives, in order to facilitate and implement local development, in both economic and social ways.

Keywords: Economic and Social Development. Municipal Fomentation. Public Administration.

Recebido em: 11/08/2016

Revisado em: 21/07/2016

Aprovado em: 30/07/2016 


\section{Introdução}

Observa-se que na disposição constitucional brasileira insere-se como objetivos da República a erradicação da pobreza e da marginalização como forma de reduzir as desigualdades sociais e regionais, bem à dignidade da pessoa humana como um dos fundamentos constante no texto constitucional brasileiro. Verifica-se a convergência necessária entre a efetiva concretização dos objetivos fundamentais em que se constitui o Estado democrático no Brasil e a participação do Município, como membro integrante da organização politico-administrativo, na utilização de sua autonomia na persecução de suas funções.

Percebe-se que na conjuntura socioeconômica, verifica-se que o desenvolvimento social não está acompanhando de forma paralela ao crescimento econômico, apresentando lacuna entre essas vertentes. Portanto vem o questionamento: qual seria a contribuição do município no desenvolvimento local? Como poderia implementar o disposto na Constituição Federal? Observa-se, sobremaneira, a responsabilidade administrativa do município de modo a viabilizar e concretizar o desenvolvimento local, tanto econômico como social.

No conjunto das funções administrativas exercidas pelo ente publico, há o Fomento como atividade administrativa na gestão do interesse público realizado pelo ente administrativo. Assim no desenvolvimento dos interesses coletivos, a administração pública, nesse caso a Administração Municipal, tem a responsabilidade de promover e incentivar o desenvolvimento local.

Assim com as diversas atribuições do município em executar as políticas urbanas fixadas pela constituição e pelo estatuto das cidades tem-se que o planejamento de ações que permitam o desenvolvimento local, como o desenvolvimento humano e econômico. O município está inserido em um contexto amplo, ou seja, é uma engrenagem fundamental dentro de um sistema. O Município no contexto democrático brasileiro seria a base da organização política e social, havendo uma relação próxima entre o administrado e o ente federado, criando maiores possibilidades de acertos nas políticas públicas. 
O Município teve sua importância reconhecida e suas responsabilidades definidas, sendo uma questão central a sua autonomia e, consequentemente, a responsabilidade de administrar e promover o desenvolvimento local, como instrumento de realização social e de bem-estar da população, constituindo uma importante ferramenta na valorização do ser humano e na construção de uma sociedade equilibrada.

Para tanto, inicialmente, o presente artigo faz uma análise sobre a posição do município como ente federativo e fomentador do desenvolvimento local como forma de atuação das funções administrativas. Em momento subsequente, busca-se compreender o fenômeno do crescimento econômico no Brasil e a relação do Município no desenvolvimento local como fator de eliminação da pobreza.

Quanto à metodologia, assinala-se a pesquisa bibliográfica, através de um estudo descritivo-analítico, ao que se consigna ao material pesquisado: legislações, doutrinas jurídicas e jurisprudências especializadas mais adequadas ao objeto do estudo.

Quanto à abordagem, é qualitativa, porquanto a tarefa é humanística, voltada, nomeadamente, aos profissionais do Direito e, por último, quanto aos objetivos, tem-se a livre metodologia descritiva e exploratória, sob o escopo de identificar, analisar e reger os institutos no ordenamento jurídico em face da experiência Administrativa brasileira.

\section{O Município como Ente Administrativo e Federativo}

A Constituição da República Federativa do Brasil de 1988 definiu um novo formato no contexto das competências e da autonomia dos Estados-membros e dos Municípios principalmente e na capacidade tributária municipal, possibilitando a autonomia financeira, por meio de repartição de competências tributarias. A autonomia no pacto federativo brasileiro, concedida aos municípios, contribui para o desempenho das atividades 
administrativas municipais dentro do contexto econômico e social de um estado democrático de direito do qual está inserido ${ }^{1}$.

A legitimação da autonomia municipal como instrumento para a promoção do crescimento socioeconômico cria meios de fortalecer a democracia e valores do sistema democrático. Assim, a organização política dos municípios exerce extrema influência na solução de problemas urbanos.

Dentre as várias competências estabelecidas no artigo 23 da Constituição Federal de 1988, tem-se que cabe ao município fomentar a produção, combater as causas da pobreza e os fatores de marginalização e promover a integração social dos diversos setores. Ora essa competência conjunta visa criar o equilíbrio e promover condições de bem estar em cooperação com os Estados e a União. Bem, como o artigo 182 estabelece que a política de urbana deve ordenar desenvolvimento e garantir bem-estar de seus habitantes.

Como forma de regulamentar os artigos 182 e 183 da Constituição Federal, na execução da política urbana foi sancionada a Lei n. 10.257, de 10 de julho de 2001, o Estatuto da Cidade, estabelecendo normas de ordem pública e de interesse social em prol do bem coletivo, do bem-estar e do equilíbrio ambiental. Objetiva o planejamento do desenvolvimento das cidades e das atividades econômicas como forma de possibilitar cidades econômicas e socialmente sustentáveis. Assim, os artigos $1^{\circ}$ e $2^{\circ}$ descrevem o seguinte:

Art. $1^{\circ} \mathrm{Na}$ execução da política urbana, de que tratam os arts. $182 \mathrm{e}$ 183 da Constituição Federal, será aplicado o previsto nesta Lei. Parágrafo único. Para todos os efeitos, esta Lei, denominada Estatuto da Cidade, estabelece normas de ordem pública e interesse social que regulam o uso da propriedade urbana em prol do bem coletivo, da segurança e do bem-estar dos cidadãos, bem como do equilíbrio

\footnotetext{
${ }^{1}$ Maria Lírida Calou de Araújo e Mendonça e Guilherme Dourado A. Sá Araújo, comentam que "[...] o direito administrativo se desenvolveu ao mesmo tempo como limitador e legitimador do exercício do poder político e tem como seus elementos estruturantes os ideais de separação dos poderes, constitucionalismo, direitos fundamentais e democracia, reunidos sob a égide de um sistema de contenção do outrora absoluto exercício do poder político." (MENDONÇA; ARAÚJO, 2014, p. 243).
} 
ambiental. Art. $2^{\circ}$ A política urbana tem por objetivo ordenar o pleno desenvolvimento das funções sociais da cidade e da propriedade urbana, mediante as seguintes diretrizes gerais: I - garantia do direito a cidades sustentáveis, entendido como o direito à terra urbana, à moradia, ao saneamento ambiental, à infra-estrutura urbana, ao transporte e aos serviços públicos, ao trabalho e ao lazer, para as presentes e futuras gerações; II - gestão democrática por meio da participação da população e de associações representativas dos vários segmentos da comunidade na formulação, execução e acompanhamento de planos, programas e projetos de desenvolvimento urbano; III - cooperação entre os governos, a iniciativa privada e os demais setores da sociedade no processo de urbanização, em atendimento ao interesse social; IV - planejamento do desenvolvimento das cidades, da distribuição espacial da população e das atividades econômicas do Município e do território sob sua área de influência, de modo a evitar e corrigir as distorções do crescimento urbano e seus efeitos negativos sobre o meio ambiente.

O constituinte reconheceu o município como ponto fundamental na afirmação da democracia, pois para este foi designado papel importante para a consolidação dos fundamentos e objetivos constitucionais. Assim, a autonomia política, a administrativa e a financeira criam meios para viabilizar as políticas destinadas aos municípios, e assim equiparando aos outros entes federados (MEIRELES, 2008, p. 44).

Hely Lopes Meireles (2008, 33-35), ressalta a necessidade do município, em ter um planejamento estratégico e maior organização, de modo a atender as conveniências locais de forma eficaz, assim afirma que "[...] o inegável é que na atualidade o município assume todas as reponsabilidades na ordenação da cidade, na organização dos serviços públicos [...] agravados pelo fenômeno avassalador da urbanização". Testifica Meireles (2008) que ao município não cabe apenas a ordenação da cidade, mas sim a responsabilidades de todos os setores que interfiram na cidade e em tudo que concerne ao bem-estar dos munícipes.

Nelson Nery Costa (2014, p. 21) afirma que o "Município é a base da organização política democrática, porque nele ocorre a verdadeira relação entre a sociedade e o Poder Público". Assim a proximidade entre o 
ente administrativo e o administrado é mais e as necessidades são claras e definidas, com maiores possibilidades de acertos em sua execução e atendimento à população. Sendo assim, não há que se falar de interesse local, que também não o seja reflexamente, dos Estados e da União, bem como o inverso é verdadeiro (MEIRELES, 2008).

Como assevera José Júlio da Ponte Neto (2008, p. 31), o modelo do município adotado pela Constituição de 1988 “[...] deve ser entendido ao longo de sua evolução histórica, desde a colonização até as suas vicissitudes [...] os municípios assumiram, a partir de 1988, a atribuição de promover o enraizamento da cultura da participação popular [...]”, como forma de corresponsabilidade para fixação das prioridades locais. Destarte, o município naturalmente seria o local do exercício social e politico do ser humano (PONTE NETO, 2008, p. 34).

O federalismo implementado pela atual Constituição Brasileira apresenta um equilíbrio na atribuição das competências e na distribuição dos poderes, como afirma Raul Machado Horta (1995, p. 526), que “[...] afastou das soluções centralizadoras de 1967 [...] as bases do federalismo de equilíbrio estão lançadas na Constituição de 1988". Rompendo com a estrutura dualista, passando o município a ser elevado ao mesmo patamar da União e dos Estados, que são "[...] reconhecidos como uma das fundamentações da estrutura social, política e econômica do país" (PONTE NETO, 2008, p. 283).

Paulo Bonavides (2007) examina que para a descentralização administrativa derivada dos preceitos constitucionais ter efeito positivo, seria necessário que essa autonomia seja realmente reconhecida e que seja garantida por meio da estruturação dos municípios:

O operador do direito precisa olhar o município sob a ótica da Constituição Federal de 1988, ou seja, uma pessoa jurídica autônoma, pujante, com diversas competências, enfim, com uma gama bastante grande de atribuições para servir à população. $\mathrm{O}$ fortalecimento do município representa, por consequência, o fortalecimento da democracia no país. Um município atuante significa menos problemas para o Estado e, por extensão, para a União. (BONAVIDES, 2007, p. 314) 
Para que o pacto federativo seja eficaz, o fortalecimento, como assevera Bonavides (2007), deve ser perseguido e implantando, pois quanto mais eficaz for o município, mais fortalecidos estarão os Estados e a União.

Gustavo Binenbojm (2008) assevera que, na desconstrução dos antigos paradigmas e a apresentação de novos objetivos, a administração pública deve assumir um novo papel frente às feições que se apresentam, principalmente no sistema de direitos fundamentais.

$\mathrm{Na}$ tarefa de desconstrução dos velhos paradigmas e proposição de novos, a tessitura constitucional assume papel condutor determinante, funcionando como diretriz normativa legitimadora das novas categorias. A premissa básica a ser assumida é a de que as feições jurídicas da Administração Pública - e, a fortiori, a disciplina instrumental, estrutural e finalística da sua atuação - estão alicerçadas na própria estrutura da Constituição, entendida em sua dimensão material de estatuto básico do sistema de direitos fundamentais e da democracia. (BINENBOJM, 2008, p. 8)

Santos (2008, p. 20) verifica que a distribuição e a democratização do poder e consequentemente, a conquista de maior autonomia "[...] provêm que estas se transformem em eficientes veículos de demandas populares, resultando em um exercício mais pleno de cidadania [...]", assim buscando aproximar, os direitos e garantias constitucionais de forma efetiva para a população.

Essas medidas, portanto, favorecem o entendimento acerca da atuação municipal, em nível social, reforçando o ideal de cumprimento das disposições constitucionais, ao lado de referência para as influências, no decorrer da história, de um Estado de Bem-Estar Social, ao qual o Brasil tentou, por diversas vezes, assimilar. É nesse sentido que Claudia do Valle Benevides (2011) reporta que o Welfare State faz referência à ação do Estado na organização e implementação das políticas de provisão do Bem-Estar, sendo na redução dos riscos sociais ou mesmo nos resultados adversos do mercado, veja-se: 
A ação estatal na organização e implementação das políticas de provisão de bem-estar, independentemente do grau em que se efetiva a participação do Estado, reduzindo os riscos sociais aos quais os indivíduos estão expostos, baseando-se em uma noção de direito social.. Também estão ligadas a uma determinada relação entre o Estado e o mercado, na qual o segundo tem alguns de seus movimentos modificados pelo primeiro de modo a se reduzir os resultados socialmente adversos do mercado. (BENEVIDES, 2011, p. 12)

A economia não teria a plena capacidade de acumular capital de forma a garantir o desenvolvimento econômico e social justo, sendo necessária a intervenção do Estado no domínio econômico, como forma até de evitar crises econômicas geradas pelo próprio capital. Nesse sentido, Antônio José Avelãs Nunes (2003, p. 32) demonstra que as bases pensamento de Keynes do welfare state seriam basicamente de "[...] natureza econômica, ligadas à necessidade de reduzir a intensidade e a duração das crises cíclicas próprias do capitalismo, e motivadas pelo objetivo de salvar o próprio capitalismo".

Deve-se, entretanto, observar que o Welfare State, como lembra Gosta Esping-Andersen (1991), o Estado de Bem-Estar Social não é só compreendido em termos de direitos e garantias, mas se deve considerar o conjunto de atos e atividades estatais que se entrelaçam com o papel do mercado.

Paulo Bonavides (2010, p. 183-186) entende o Welfare State como uma transformação estrutural do Estado estendendo a sua influência onde antes era controlado pela iniciativa privada:

Quando o Estado, coagido pela pressão das massas, pelas reivindicações que a impaciência do quarto estado faz ao poder político, confere, no Estado constitucional, ou fora deste, os direitos do trabalho da previdência, da educação, intervém na economia como distribuidor, dita o salário, manipula a moeda, regula os preços, combate o desemprego, protege os enfermos, dá ao trabalhador e ao burocrata a casa própria, controla as profissões, compra a produção, financia as exportações, concede crédito, institui comissões de abastecimento, provê necessidades individuais, enfrenta crises 
econômicas, coloca na sociedade todas as classes na mais estreita dependência de seu poderio econômico, político e social, em suma, estende sua influência a quase todos os domínios que dantes pertenciam, em grande parte, à área de iniciativa individual, nesse instante o Estado pode, receber com justiça a denominação de Estado Social.

Verifica-se, portanto, que é o conjunto de políticas de entrelaçamento entre garantias individuais e o mercado, em busca de equilíbrio, como forma de evitar comportamento do mercado que possa ser inadequado ao desenvolvimento social. E são essas medidas que o município, no atendimento de princípios específicos aplicáveis à Administração Pública, dentre os quais se incluem o da eficiência, deverá almejar cumprimento.

\section{As Modalidades de Intervenção do Estado na Economia e o Papel do Município na sua Concretização}

A intervenção do Estado no domínio econômico, este estabelecido como ambiente eminentemente privado, pode se dar de forma direta ou indireta. Conforme Eros Roberto Grau (1991, p. 162), tem-se disposição de hipóteses excepcionais do artigo 173, caput, bem das hipóteses taxativas dos artigos 21 e 177 da Constituição da República Federativa do Brasil, de 1988, que tornam legítima a intervenção direta, na economia, mediante exploração estatal de atividade econômica. Da qualquer modo, essa forma de atuação caracteriza uma intervenção no domínio econômico, que pode se dar sob modalidades de: absorção (uma atuação em regime semelhante ao de monopólio) e de participação (uma atuação em regime de ampla competição e concorrência).

Entretanto, fora dessas hipóteses excepcionais de intervenção direta, caberá ao Estado, ainda conforme Eros Roberto Grau (1991, p. 162) apenas intervir indiretamente na economia, na qualidade de um agente normativo e regulador, conforme o texto constitucional, da atividade econômica, e, nesse caso, não será possível se estabelecer um caso de intervenção direta na economia, mas uma atuação sobre o domínio econômico, que, conforme, mais uma vez, a Constituição da República Federativa 
do Brasil, de 1988, poderá ocorrer por três formas distintais, quais sejam: por fiscalização; por incentivo e, finalmente, mediante planejamento.

Inicialmente, verifica-se que a atividade fiscalizatória da atividade econômica, prescrita no artigo 174 da Constituição vigente, conecta-se com a ideia de exercício de poder de polícia, aplicado em relação aos direitos econômicos, ou seja, sobre o desempenho das atividades econômicas. Tanto que, defende Tácio Lacerca da Gama, que será custeada não pelo preço do bem ou serviço realizado ou comercializado, como ocore nos casos de intervenção direta, mas mediante a exigência de uma taxa pelo exercício do poder de polícia, com base no artigo 145, inciso II, do texto constitucional.

Por sua vez, o planejamento, o qual é rejeitado por Eros Roberto Grau como forma de intervenção do Estado no domínio econômico, por conceber que se qualifica apenas com as formas de intervenção, consiste no empreendimento de atuação legislativa, conforme previsto no artigo

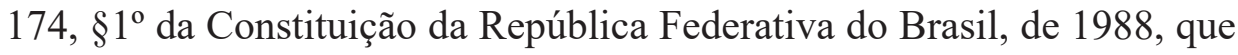
assim defende: "A lei estabelecerá as diretrizes e bases do planejamento do desenvolvimento nacional equilibrado, o qual incorporará e compatibilizará os planos nacionais e regionais de dsenvolvimento". Portanto, uma atuação do Estado dependerá, nesse caso, de manifestação do Poder Legislativo, custeada com os recursos advindos da cobrança de impostos.

Finalmente, caberá a intervenção no domínio econômico mediante incentivo quando o Estado promoverá, mediante um regime de induções de comportamento, a movimentação financeira para o alcance dos objetivos fundamentais. Para tanto, é custeada, em muitos casos, pelas Contribuições de Intervenção no Domínio Econômico.

O município, por sua vez, detém, por disposição expressa da Constituição da República Federativa do Brasil, de 1988, em seus artigos $1^{\circ} \mathrm{e}$ 18, competência legislativa e política privada, para o exercício de regulação de interesses próprios, ou seja, de interesse local, que consubstanciam a própria formação federativa do Estado brasileiro.

Nesse contexto, há de serem ressaltadas as atribuições conferidas ao município, assegurando-lhe o direito de legislar supletivamente so- 
bre Direito Econômico e do Consumidor, conforme disposição, também expressa, do artigo 24, incisos I e V, bem como do artigo 30, inciso I e II, e, ainda, 115 do texto constitucional. Essa medida, para Giovani Clark (2001, p. 94-95), é que traça as competências concorrentes, previstas pela Constituição vigente, para o intervencionismo econômico municipal. Portanto, quando se permite à União e aos Estados-membros legislar sobre certas matérias (à União, editar as normas gerais; aos demais entes, suplementá-las para atender às suas peculiaridades), permite-se, pelos dispositivos citados, que o município possa suplementar a legislação estadual e a federal no que couber, para atender aos interesses locais.

Em consequência, permite-se que o município possa intervir diretamente, por intermédio de empresas estatais, ou ainda indiretamente, por meio de legislação suplementar de controle de preços e sua aplicação com sanções administrativas aos infratores, e que possa, ainda, regular o espaço urbano, conforme previsão constante do artigo 182 da Constituição vigente, o qual assim dispõe sobre a política de desenvolvimento urbano, executada pelo Poder Público municipal, conforme diretrizes gerais fixadas em lei, e tem, por âmbito geral, ordenar o pleno desenvolvimento das funções sociais da cidade e garantir o bem-estar de seus habitantes. E é o que fazem os municípios, com o Estatuto da Cidade.

Assim, conforme disposição de Giovani Clark e Rodrigo de Castro Lucas (2014, p. 83), caberá ao município, inicialmente, como ente integrante da República Federativa do Brasil, competência que lhe confere o poder-dever de ordenar o pleno desenvolvimento das funções sociais da cidade, legislar em matéria de Direito Econômico e do Consumidor, para $o$ atendimento de interesses locais.

Da mesma forma, já se posicionou o Supremo Tribunal Federal, acerca do tema, defendendo a atuação do município na seara econômica e consumerista, almejando o cumprimento das disposições constitucionais. Assim, conforme disposições ADIn de n. 1.950/SP, relatada pelo Ministro Eros Roberto Grau:

Afasto desde logo a alegação de inconstitucionalidade formal. Bem ao contrário do que sustenta a requerente, não apenas a União pode 
atuar sobre o domínio econômico, isto é, na linguagem corrente, intervir na economia. Não somente a União, mas também os Estados-membros e o Distrito Federal, nos termos do disposto no artigo 24, inciso I, da Constituição do Brasil, detêm competência concorrente para legislar sobre direito econômico. Também podem fazê-lo os Municípios, que, além de disporem normas de ordem pública que alcançam o exercício da atividade econômica, legislam sobre assuntos de interesse local, aí abrangidos os atinentes à sua economia, na forma do artigo 30 , inciso $\mathrm{I}$, da $\mathrm{CB} / 88$.

E, da mesma forma, na seara consumerista, dispõe julgado referente ao Supremo Tribunal Federal, favorável à autonomia dos Municípios para legislar sobre assunto de interesse local, envolvendo relação de consumo, no AI n. 347.717 - AgR, com relatoria do Ministro Celso de Mello, em 2005, que:

O Município pode editar legislação própria, com fundamento na autonomia constitucional que lhe é inerente (CF, art. 30, I), com o objetivo de determinar, às instituições financeiras, que instalem, em suas agências, em favor dos usuários dos serviços bancários (clientes ou não), equipamentos destinados a proporcionar-lhes segurança (tais como portas eletrônicas e câmaras filmadoras) ou a propiciar-lhes conforto, mediante oferecimento de instalações sanitárias, ou fornecimento de cadeiras de espera, ou, ainda, colocação de bebedouros. Precedentes.

Complemente-se, ainda, que o Supremo Tribunal Federal, acerca da intervenção municipal no consumo (atividade este que gera impactos imediatos na economia), na Súmula de n. 645, já firmou entendimento de que cabe ao Município fixar o horário de funcionamento de estabelecimento comercial.

Verifica-se, portanto, que a atuação municipal na economia, conforme disposições constitucionais, poderá ocorrer nas mais diversas formas, inclusive aqueles diretas. E, nesse sentido, há de se defender uma postura não apenas para atendimento de fins econômicos, mas, também, por força constitucional, de fins sociais. 


\section{A Administração Pública e o Cumprimento do Princípio da Eficiência}

O entendimento contemporâneo da atuação da Administração Pública não deve ser analisado sob um prisma somente formal, com a finalidade de executar os mandamentos normativos que lhe são apresentados, mas deve-se analisar sob uma maior perspectiva, pois o que a torna peculiar em relação às outras esferas do poder é a capacidade-dever de satisfazer os imperativos legais em relação aos administrados. O conteúdo de atuação da administração deve-se, para atender plenamente seu conteúdo, pautar-se de diversos princípios, dentre eles o da eficiência, como forma de concretizar a efetiva realização no atendimento de suas atribuições.

A atividade administrativa com a orientada para a satisfação das tarefas do Estado e para a satisfação dos interesses coletivos, essa busca com fins heterônomos, com a finalidade de atingir o proposito legal dos interesses gerais ou comuns a faz parte da própria atuação como ente administrativo.

Para o desempenho da função administrativa foram estipulados princípios que fixam, direcionam a atividade estatal, mesmo que a Constituição discipline diversas situações, a artigo 37 do texto constitucional, em seu caput, determina que "[...] a administração pública direta e indireta de qualquer dos Poderes da União, dos Estados, do Distrito Federal e dos Municípios obedecerá aos princípios de legalidade, impessoalidade, moralidade, publicidade e eficiência [...]", fixando assim o regime jurídico inerente ao exercício estatal.

Dentre os princípios destacados, tem-se que o princípio da eficiência poderia maximizar a atuação do Estado na busca do bem-estar das pessoas, bem como na solução de vários interesses públicos. Nesse sentido, Canotilho (2009, p. 1.224) assevera que é "[...] sobretudo invocado no âmbito dos direitos fundamentais (no caso de dúvidas deve preferir-se a interpretação que reconheça maior eficácia aos direitos fundamentais)".

O princípio da eficiência, no conceito de Hely Lopes Meireles (1996, p. 90), na atuação do agente público poderia ser considerado na maneira de atuar do agente público, na busca de melhores resultados e 
na prestação do serviço público, assim o agente público deve "[...] realizar suas atribuições com presteza, perfeição e rendimento funcional [...] exigindo resultados positivos para o serviço público e satisfatório atendimento das necessidades da comunidade e de seus membros".

Maria Sylvia Zanella Di Pietro (2014, p. 272) observa que a falta de eficiência administrativa ocorre por diversos fatores como: "[...] a inércia do poder público, a sua ineficiência, a ausência ou deficiência no planejamento, a corrupção, os desvios de finalidade na definição de prioridades". Nesse contexto Raquel Machado (2014, 144-145) assevera que "[...] importa perceber que a falta de eficiência da Administração Pública, mais do que uma questão política, financeira e administrativa, fere, em seu íntimo, a dignidade humana [...]", ou seja, o Estado ineficiente não contribui para o desenvolvimento, torna-se falho no cumprimento das demandas vinculadas a ele, a ineficiência torno-o burocrático e facilitam a inserção da corrupção em seu meio ${ }^{2}$.

O princípio da eficiência poderia ser entendido como as ações do Estado de forma adequada para atendimento do interesse coletivo e claro aos anseios públicos. Deve o ente administrativo realizar suas atribuições com eficiência, com perfeição a fim de conseguir o melhor desempenho no cumprimento das demandas. Assim aos determinar "[...] políticas econômicas progressistas, as leis jurídico-econômicas devem buscar a eficiência social para a adjudicação dos diversos fatores de produção objetivando o desenvolvimento e a garantia da seguridade" (GONÇALVES; STELZER, 2013, p. 283).

\footnotetext{
${ }^{2}$ Raquel Machado (2014, p. 145) afirma que em relação ao princípio da eficiência, este “[...] não pode ser compreendido de forma reducionista e parcial, relacionado apenas à otimização dos meios empregados pela Administração e à boa estruturação de suas instalações e atividades intermediárias. Trata-se de direito fundamental do cidadão, que tem relação direta com a dignidade e com a crença na validade do Ordenamento Jurídico, quanto à expectativa na qualidade dos serviços prestados".
} 


\section{O Fomento como Desenvolvimento Social e Econômico Local}

A prioridade do Estado brasileiro (política, social, econômica e jurídica) passa ser o humano, em todas as dimensões, com uma estrutura voltada para o bem-estar e desenvolvimento do mesmo, colocando-o como centro do universo jurídico-constitucional, reconhecendo que um dos fins do Estado é proporcionar as condições mínimas para que as pessoas tenham dignidade (HOLANDA, 2014).

Esse mínimo de condições para a dignidade pode ocorrer por meio da função transformadora da atividade estatal, onde o poder público deve contribuir para as realizações no campo do direito econômico e contribuindo com o desenvolvimento social, Eros Roberto Grau (2008, p. 53) descreve a ordem econômica como [...] o conjunto de normas que define, institucionalmente, um determinado modo de produção econômica".

Paes de Barros (2000) afirma: o Brasil não é um país em sua essência pobre, mas um país com uma enorme quantidade de pobres. E que essa estrutura se apresenta tendo como causa principal a "[...] perversa desigualdade na distribuição da renda e das oportunidades de inclusão econômica e social" (PAES DE BARROS, 2000, p. 123). O autor assevera que ao Estado brasileiro seja imperativo criar estratégias para estimular tanto o crescimento econômico, como o desenvolvimento social, como eliminação da desigualdade social no País:

É imperativo reduzir a desigualdade tanto por razões morais, como por motivações relativas à implementação de políticas eficazes para erradicar a pobreza. A tradição brasileira, contudo, tem reforçado a via única do crescimento econômico, sem gerar, como vimos, resultados satisfatórios no que diz respeito à redução da pobreza. É óbvio que reconhecemos a importância crucial de estimular políticas de crescimento para alimentar a dinâmica econômica e social do país. No entanto, para erradicar a pobreza no Brasil é necessário definir uma estratégia que confira prioridade à redução da desigualdade. (PAES DE BARROS, 2000, p. 141) 
Paulo Bonavides (1989) alega que os preceitos constitucionais que têm relação com os direitos econômicos implicam uma garantia que possa dar estabilidade às situações jurídicas criadas pelo legislador. A intervenção do Estado na ordem econômica, não quer dizer que o Estado assumirá para si todos os setores da economia.

Clèmerson Merlin Clève (2003, p. 388) afirma que o Estado é uma realidade instrumental, que "[...] é uma máquina concebida pelo constituinte para buscar a plena efetividade, a plena concretização dos princípios, dos objetivos e dos direitos fundamentais". Dessa maneira, o Estado deve atuar de modo sincronizado, administrando, legislando e julgando, todos com um objetivo, qual seja “[...] buscar a plena satisfação dos direitos fundamentais. Quando o Estado se desvia disso, ele está, do ponto de vista político, se deslegitimando, e do ponto de vista jurídico, se desconstitucionalizando" (CLÈVE, 2003, p. 388).

Vasco Pereira da Silva $(2003$, p. 81) afirma que com a "[...] passagem do Estado liberal ao social, a administração pública deixa de ser concebida como meramente executiva, para se tornar cada vez mais numa atividade prestadora e constitutiva [...]”, de modo que a administração pública convocou para si "[...] um conjunto de tarefas que não se esgotam na noção de aplicação da lei ao caso concreto, ou de execução do direito [...]", mas sim uma nova ideia de função administrativa que alargou as competências da atividade estatal.

Marques Neto (2010, p. 6) conceitua o fomento como a "[...] atividade estatal de incentivo positivo ou negativo a outra atividade desenvolvida por um ou vários particulares, de forma a condicionar o comportamento privado". Assim a atividade de fomento do município pode ser realizada em vários setores, desde o implemento do turismo, como o incentivo fiscal as empresas que se instalarem em sua área de abrangência. Como observa Barroso (2008, p. 16), cabe ao Poder Público Municipal, na persecução de seus objetivos, estimular "[...] comportamentos da iniciativa privada que conduzam a esses resultados, oferecendo vantagens fiscais, financiamentos, dentre outras formas de fomento".

Rawls (1997, p. 64) afirma que, pelos princípios da justiça, as pessoas devem ter direitos e liberdades iguais, e para os membros menos 
favorecidos, “[...] as desigualdades sociais e econômicas devem ser ordenadas de tal modo que sejam ao mesmo tempo consideradas como vantajosas para todos dentro dos limites do razoável [...]", como benefícios compensatórios. Dessa forma, admite que o Estado fiscalize a atividade econômica, a fim de garantir a distribuição equitativa de oportunidades, estabelecendo medidas protetivas, incluindo a necessidade de o governo garantir um mínimo social.

[...] suponho que há uma igualdade de oportunidades que é eqüitativa (em oposição a uma igualdade formal). Isso significa que, além de manter as formas habituais de despesas sociais básicas, o governo tenta assegurar oportunidades iguais de educação e cultura para pessoas semelhantemente dotadas e motivadas, seja subsidiando escolas particulares seja estabelecendo um sistema de ensino público. Também reforça e assegura a igualdade de oportunidades nas atividades econômicas e na livre escolha de trabalho. Isso se consegue por meio da fiscalização de empresas e associações privadas e pela prevenção do estabelecimento de medidas monopolizantes e de barreiras que dificultem o acesso às posições mais procuradas. Por último, o governo garante um mínimo social, seja através de um salário-família e de subvenções especiais em casos de doença e desemprego, seja mais sistematicamente por meio de dispositivos tais como um suplemento gradual de renda (o chamado imposto de renda negativo). (RAWLS, 1997, p. 303-304)

O fomento pela Administração torna-se importante com o surgimento de atividades econômicas exercidas pelo Estado que se transforma em agente condutor básico das transformações, seria o fenômeno da "[...] constitucionalização do direito administrativo e a adoção do sistema de direitos fundamentais e do sistema democrático traduzidos em princípios e regras constitucionais - a pautar a atuação da Administração Pública”. Assim a atuação administrativa deve usar como pressuposto a dignidade da pessoa humana (BINENBOJM, 2008).

O fomento pela administração municipal no interesse de desenvolver a economia local e consequentemente criando postos de trabalhos com aumento efetivo da renda do cidadão, pode incentivar o comporta- 
mento, seja por indução, seja por participação, ou mesmo por absorção, condicionando e incentivando a atividade econômica (GRAU, 2008, p. 147). O fomento seria a

[...] atividade administrativa que busca influenciar o comportamento dos particulares mediante benefícios e estímulos e não através de imposições, de modo a induzi-los a desempenharem atividades tidas como necessárias ao atendimento do interesse público. (MELLO, 2010, p. 4)

Apesar de a atuação econômica ter sido quase que integralmente mitigada para o meio empresarial, como agente econômico, o Estado pode por meio de regulação econômica atuar em na economia com o fim de atender as demandas sociais, senão veja-se o que afirma Clèmerson Merlin Clève (2009, p. 211):

Ainda que tenha restado bem mitigada a atuação estatal como provedor de bem ou serviço, isto é, como agente econômico, o Estado não só pode como deve exercitar integralmente a intervenção indireta por meio da regulação jurídica e do fomento, inclusive porque a Carta de 1988 rejeita o absenteísmo estatal, isto é, o Estado Brasileiro não pode manter-se inerte diante das demandas econômico-sociais e ao desafio da soberania nacional.

Marques Neto (2010) afirma que a atividade de fomento, quando condiciona o comportamento dos particulares, principalmente no incentivo das atividades privadas, é imprescindível que não colida com outros valores constitucionais e, claro, na demonstração efetiva do interesse público como forma de justificar tal medida:

A atividade estatal de fomento apresenta-se, hoje, como relevante instrumento de intervenção do Estado no domínio econômico, possuindo o Direito Público brasileiro expressivos exemplos práticos. Trata-se de atividade estatal de condicionamento do comportamento dos particulares, essencialmente de incentivo ou apoio a atividades privadas de forma a torná-las mais viáveis, interessantes ou abrangentes. Como qualquer outro instrumento de interven- 
ção, o fomento encontra limites de abrangência ou parâmetros de incidência, em consonância com o próprio modelo de organização econômica conferido pela Constituição Federal. Os princípios da subsidiariedade e da proporcionalidade consistem nos principais parâmetros de incidência do fomento administrativo, imprescindíveis para que o fomento não colida com valores outros apresentados na Carta, como a valorização do trabalho humano e a livre iniciativa. Demonstrar a existência de interesse público suficiente para justificar o fomento estatal e eleger objetivamente os beneficiários da medida administrativa com base em fatores aferíveis. (MARQUES NETO, 2010, p. 9)

O Município em sua atuação administrativa, na promoção do fomento, pode, conforme Paul Singer (2012, p. 124), estimular “" [...] novas forças produtivas e de instauração de novas relações de produção, de modo a promover um processo sustentável de crescimento econômico". Afirma ainda que esse objetivo almejado "[...] deve ser a criação de novas formas de organização da produção com lógica incluidora, ou seja, que ofereça a chance real de trabalhar com autonomia e de ganhar um rendimento suficiente para ter um padrão de vida digno" (SINGER, 2012, p. 124).

O Município na regulação da economia pode interferir na atividade econômica disciplinando-a, preservando e promovendo sempre tendo com guia os princípios que regem a administração pública. A inserção na economia visa criar meios para contribuir ao desenvolvimento local, como forma incentivar a economia municipal e consequentemente a própria arrecadação de impostos que servirá para investimento nas áreas sociais e econômicas. Na verdade, o fomento realizado pelo Município vai criam condições para a elevação econômica e social local.

Por muitas vezes, em pequenos Municípios, não há indústrias, fábricas, confecções, por vezes uma incipiente agricultura de subsistência ou qualquer outra atividade econômica que não possua a capacidade de impulsionar o desenvolvimento. Cabendo ao município por meio de suas políticas públicas de fomento dar o "start", o impulso, fazer iniciar uma atividade para que a economia comece a funcionar e a trazer benéficos como consequência, empregos, investimentos e desenvolvimento. 
O fomento local promovido pelo Município dentro de um grau de eficiência e comprometimento social, alicerçado a boas práticas administrativas, contribui para o atendimento e cumprimento das metas da administração pública. Não se pode mais esperar uma administração estritamente composta no cumprimento da lei, mas sim em seu exercício legal e na busca da efetividade dos mandamentos constitucionais atingindo o fim esperado nos fundamentos da República.

\section{Conclusão}

Apresentados os aspectos da pesquisa, com pertinência crítica e valorativa, reafirma-se que o Município como integrante do sistema político e administrativo brasileiro é um importante instrumento para a concretização das potencialidades humanas e como fomentadora do desenvolvimento social, proporcionando a harmonia entre o crescimento econômico e social.

O Estado democrático não tem convivência pacífica com os extremos, ou seja, não permite a possibilidade de desigualdades de modo a tornar incompatíveis os objetivos democráticos. Cabe ao Município, dentro de suas competências e potencialidades buscar continuadamente o progresso local, sempre com viso direcionada para o interesse coletivo e nas melhores praticam administrativas.

A atuação dos municípios na economia não teria somente um aspecto de dever, mas um direito do administrado com o fim de obter um desenvolvimento do município que crie condições para o crescimento da economia e o desenvolvimento social. A atuação do município.

O Crescimento local está relacionado, intrinsicamente, da forma como o município intervém na economia, seja nas leis orçamentarias, seja na programação de áreas de desenvolvimento, seja no incentivo fiscal para a instalação de indústrias ou serviços. Assim, a competência dos municípios para fomentar o desenvolvimento local seria atende os próprios ditames da Constituição de 1988. 
O Município tem aptidão para atuar no domínio econômico, quando o interesse é local. Principalmente quando tem necessidade de criar uma articulação com a economia de livre mercado, podendo, portanto, se utilizar das regras mercadológicas nos serviços públicos e, principalmente, nas atividades de fomento, com a finalidade de atender os próprios interesses, concernente com a administração como pública, bem como os interesses sociais, promovendo o desenvolvimento de forma equilibrada.

Do exposto, a contribuição do Município no desenvolvimento local seria a própria atividade de fomento, pois ao contribuir para o desenvolvimento na redução da pobreza, na ampliação da educação e no crescimento da economia, está consequentemente atendendo aos fundamentos e objetivos constitucionais. A administração local é peça fundamental na complexa máquina estatal, e, portanto, o seu desenvolvimento de cunho social e econômico afeta diretamente todos os entes que compõem a estrutura administrava.

\section{Referências}

BARROSO, Luís Roberto. A Ordem Econômica Constitucional E Os Limites À Atuação Estatal No Controle De Preços. Revista Eletrônica de Direito Administrativo Econômico (REDAE), Salvador, Instituto Brasileiro de Direito Público, n. 14, maio-junho-julho, 2008.

BENEVIDES, Claudia do Valle. Um Estado de Bem-Estar Social no Brasil? 2011. 98 p. Dissertação (Mestrado em Direito) - Universidade Federal Fluminense, Niterói, RJ, 2011.

BINENBOJM, Gustavo. A constitucionalização do direito administrativo no brasil: um inventário de avanços e retrocessos. Revista Eletrônica sobre a Reforma do Estado (RERE), Salvador, Instituto Brasileiro de Direito Público, n. 13, março-abril-maio, 2008.

BINENBOJM, Gustavo. As Parcerias Público-Privadas (PPPs) e a Constituição. Revista Eletrônica de Direito Administrativo Econômico (REDAE), Salvador, Instituto de Direito Público da Bahia, n. 2, maiojunho-julho, 2005. 
BONAVIDES, Paulo. Direito Constitucional. 20. ed. atual. São Paulo: Malheiros, 2007.

BONAVIDES, Paulo. Direito Constitucional. 25. ed. atual. São Paulo: Malheiros, 2010.

BONAVIDES, Paulo; ANDRADE, Paes de. História constitucional do Brasil. Brasília, DF: OAB, 1989.

CAVALCANTI, Ludmila. A Perspectiva de Gênero nas Políticas Públicas: políticas para quem? In: BRASIL. Democracia e Gênero no Legislativo Municipal. Instituto Brasileiro de Administração Municipal (IBAM), 2009.

CLARK, Giovani. O Município em Face do Direito Econômico. Belo Horizonte Del Rey, 2001.

CLARK, Giovani; LUCAS, Rodrigo de Castro. A Intervenção Municipal no Domínio Econômico: o caso dos preços abusivos praticados pelos Estacionamentos Privados em Belo Horizonte. In: MEZZAROBA, Orides et al. (Coord.) Direito e Economia. Curitiba: Clássica Editora, 2014. p. 79-99.

CLÈVE, Clèmerson Merlin. O controle da constitucionalidade e a efetividade dos direitos fundamentais. In: SAMPAIO, José Adércio Leite (Coord.). Jurisdição constitucional e direitos fundamentais. Belo Horizonte: Del Rey, 2003. p. 385-393.

CLÈVE, Clèmerson Merlin. Preceitos constitucionais fundamentais da República Federativa do Brasil, serviço público portuário e autorização para exploração de atividade portuária por meio de terminais privativos de uso misto. In: DALLARI, Adilson Abreu. Regulação portuária e concorrência - pareceres jurídicos e econômicos. Rio de Janeiro: Abratec, 2009. p. 199-246.

COSTA. Nelson Nery. Direito municipal brasileiro. 6. ed. Rio de Janeiro: Forense, 2014

DI PIETRO, Maria Sylvia Zanella. Direito administrativo e dignidade da pessoa humana. Revista Digital de Direito Administrativo, Brasil, v. 1, 
n. 2, p. 260-279, mar. 2014. Disponível em: <http://www.revistas.usp.br/ rdda/article/view/74853>. Acesso em: 7 ago. 2015.

ESPING-ANDERSEN, G. As três economias políticas do Welfare State. Revista Lua Nova, São Paulo, n. 24, p. 85-116, set. 1991.

GAMA, Tácio Lacerda. Contribuições de intervenção no domínio econômico. São Paulo: Quartier Latin, 2003.

GONÇALVES, Everton das Neves; STELZER, Joana. Princípio da Eficiência Econômico-Social no Direito Brasileiro: a tomada de decisão normativo-judicial. Seqüência: Estudos Jurídicos e Políticos, Florianópolis, v. 35, n. 68, p. 261-290, jun. 2014.

GRAU, Eros Roberto. A ordem econômica na Constituição de 1988. 2. ed. São Paulo: Malheiros, 1991.

GRAU, Eros Roberto. A ordem econômica na Constituição de 1988. 13. ed. São Paulo: Malheiros, 2008

HOLANDA, Marcus Mauricius. Análise constitucional do acesso ao trabalho digno, como instrumento do desenvolvimento econômico e social. Rio de Janeiro: Lumen Juris, 2014.

HORTA. Raul Machado. Estados de Direito Constitucional. Belo Horizonte. Del Rey, 1995

MARQUES NETO, Floriano Peixoto de Azevedo. O fomento como instrumento de intervenção estatal na ordem econômica. Revista de Direito Público da Economia - RDPE, Belo Horizonte, ano 8, n. 32, out.-dez. 2010.

MEIRELES, Hely Lopes. Direito administrativo brasileiro. São Paulo: Malheiros, 1996.

MEIRELLES, Hely Lopes. Direito municipal brasileiro. 16. ed. Atualizada por Célia Marisa Prendes e Márcio Schneider Reis. São Paulo: Malheiros, 2008.

MELLO, Rafael Munhoz de. Atividade de Fomento e o Princípio da Isonomia. Revista Eletrônica de Direito Administrativo Econômico 
(REDAE), Salvador, Instituto Brasileiro de Direito Público, n. 21, fevereiro-março-abril, 2010.

MENDONÇA, Maria Lirida Calou de Araújo; ARAÚJO, Guilherme Dourado Aragão Sá. Constituição, Direitos Fundamentais E Democracia: A Constitucionalização Do Direito Administrativo Moderno. CONPEDI/UFPB. Coordenadores: Filipe Reis Melo, Maria Lírida Calou de Araújo e Mendonça, Yuri Schneider. Florianópolis: CONPEDI, 2014.

NUNES, Antonio José Avelãs. Neoliberalismo e direitos humanos. Rio de Janeiro: Renovar, 2003.

PAES DE BARROS, Ricardo. Desigualdade e Pobreza no Brasil. Retrato de uma Estabilidade Inaceitável. Revista Brasileira de Ciências Sociais, [S.l.], v. 15, n. 42, 2000.

PONTE NETO, José Júlio da. Poder público local e cidadania: atores políticos sociais na construção da democracia participativa no município de Fortaleza. Fortaleza. Unifor, 2008

RAWLS, John. Uma teoria da justiça. Tradução de Almiro Pisetta e Lenita M. R. Esteves. São Paulo: Martins Forense, 1997.

SANTOS, Ângela Moulin S. Penalva. Município, descentralização e território. Rio de Janeiro: Forense, 2008.

SILVA, José Afonso da. A dignidade da pessoa humana como valor supremo da democracia. Revista de Direito Administrativo, Rio de Janeiro, n. 212, p. 88-94, abr.-jul. 1998.

SINGER, Paul. Globalização e desemprego: diagnóstico e alternativas. 8. ed. São Paulo: Contexto, 2012.

Maria Lírida Calou de Araújo e Mendonça é pós-doutora em Direito pela Universidade Federal de Santa Catarina (UFSC), doutora em Direito Público pela Universidade Federal de Pernambuco (UFPE), mestre em Direito e Desenvolvimento pela Universidade Federal do Ceará (UFC), professora 
titular do Programa de Pós-graduação em Direito Constitucional - Mestrado e Doutorado - e professora dos cursos de graduação em Direito e Pós-graduação lato sensu (Escola do Direito) da Universidade de Fortaleza, coordenadora e professora titular do curso de Direito da Faculdade Católica Rainha do Sertão (Quixadá - CE) e coordenadora-chefe do Grupo de Estudos e Pesquisas em Direito Administrativo e Tributário (GEPDAT).

E-mail: liridacalou@unifor.br.

Endereço profissional: Universidade de Fortaleza, Centro de Ciências Jurídicas, Av. Washington Soares n. 1.321, Edson Queiroz, Fortaleza, Ceará - 60811-905.

Marcus Mauricius Holanda é doutorando em Direito Constitucional e Teoria Política pela Universidade de Fortaleza (UNIFOR/CE) com bolsa da Fundação Cearense de Apoio ao Desenvolvimento Científico e Tecnológico (FUNCAP), mestre em Direito Constitucional e Teoria Política pela mesma Universidade, especialista em Direito do Trabalho e Processual Trabalhista pelo Centro Universitário Christus (UNICHRISTUS), professor do curso de graduação em Direito da Faculdade Luciano Feijão (FLF) em Sobral - CE e advogado.

E-mail:mm_holanda@yahoo.com.br.

Endereço profissional: Faculdade Luciano Feijão, Rua José Lopes Pontes n. 400, Dom Expedito, Sobral, Ceará - 62050-215. 
